\title{
A NEW METHOD OF EVALUATING THE DEGREE OF THE POSTOPERATIVE INFLAMMATORY RE- ACTION IN CATARACT SURGERY WITH IOL IMPLANTATION
}

\section{A. M. Petrunya, Yu. F. Solyanik}

There were studied 378 patients with senile cataract at the age from 42 to 76 . In the postoperative period 262 patients had areactive course, 96 had development of the postoperative inflammatory reaction (PIR) of the $1^{\text {st }}$ degree (by N. M. Sergienko's classification, 1990), 20 had IPR of the $2^{\text {nd }}$ degree. In the postoperative period the patients with cataract were noted to have the increase in the cornea thickness, revealed by the method of pachimetry, which degree of expressiveness corresponds to the degree of IPR expressiveness.

The increase of the pachimetry indicator of up to 645.0 microns corresponds to the areactive course, from 645.1 to 746.8 microns - PIR of the $1^{\text {st }}$ degree, above 746.8 microns - PIR of the $2^{\text {nd }}$ degree.

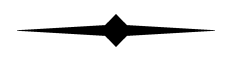

УДК 617.736-007.243-089.168

\section{ИНТРАВИТРЕАЛЬНОЕ ВВЕДЕНИЕ РАСШИРЯЮЩЕГОСЯ ГАЗА КАК МЕТОД ХИРУРГИЧЕСКОГО ЛЕЧЕНИЯ ПАЦИЕНТОВ С ИДИОПАТИЧЕСКИМИ МАКУЛЯРНЫМИ РАЗРЫВАМИ}

\author{
С. С. Родин, Н. Н. Уманец, Е. Г. Бражникова, А. Р. Король, Е. В. Ковалева
}

ГУ «Институт глазных болезней и тканевой терапии им. В. П. Филатова НАМН Украины»

\begin{abstract}
Запропонований спосіб хірургічного лікування ідіопатичних макулярних розривів сітківки шляхом інтравітреального введення газу, що розширюється, і вивчена ефективність його застосування на 44 очах. Метод значно менш інвазивний, ніж комплексна вітректомія, значно економніший. Функціональний позитивний результат лікування був отриманий у всіх випадках (100\%), анатомічного прилягання країв розриву сітківки було досягнуто у 88 \% випадків, повне зникнення макулярного розриву відбулося на 56,8 \% очей із стадіями II-IV без проведення вітректомії, а у пацієнтів з другою стадією - у 82,2\% випадків.
\end{abstract}

Ключевые слова: идиопатические макулярные разрывы, расширяющийся газ

Ключові слова: ідіопатичні макулярні розриви, газ, що розширюється.

Введение. Хирургическое лечение идиопатических макулярных разрывов широко используется в мировой витреоретинальной практике. В настоящее время витрэктомия с удалением задней гиалоидной мембраны и внутренней пограничной мембраны, с последующей газовой или силиконовой тампонадой является повседневной операцией в ведущих витреоретинальных центрах. Преимущества хирургии идиопатических разрывов сетчатки доказаны рядом [2-7] исследований. Однако, наряду с усовершенствованием технологий и с повышением частоты положительного результата применения витрэктомии при идиопатических макулярных разрывах в стадиях II-IV [8, 9], в литературе описаны случаи, когда пациенты страдают от негативных последствий внутриглазной хирургии. Отмеченные осложнения включают ускорение развития катаракты у $80 \%$ больных [10]. Banker A.S. с соавторами сообщают, что различные осложнения в заднем сегменте глаза отмечаются в $41 \%$ пациентов [11]. Осложнения включают в себя как легкие - изменение пигментного эпителия сетчатки (33\%), так и потенциально серьезные осложнения - отслоение сетчатки (11\%), кистозный макулярный отек, де- фекты поля зрения, хориоидальная неоваскуляризация и эндофтальмиты [11, 12].

В связи с этим актуальным является вопрос разработки менее травматичных методов лечения идиопатических макулярных разрывов.

Цель настоящего исследования - разработать и изучить эффективность нового метода лечения идиопатических макулярных разрывов (Пат. № 200800253 А Украины, МПК А61В3/00 от 10.09.08; БюЛ. № 1, 20080).

МАТЕРИАЛ И МЕТОДЫ. Исследование проводилось с 1995 года. За этот период под нашим наблюдением находился 41 пациент, возрастом от 58 до 75 лет (64,5士7). В исследование включены 34 женщины и 7 мужчин. Идиопатический макулярный разрыв был в 44 глазах, т.е. у трех пациентов разрыв сетчатки был двусторонним. Из исследования были исключены пациенты, макулярные разрывы у которых возникли в результате травмы, осложненной миопии, эпиретинальных мембран и витреомакулярного тракционного синдрома. Длительность существования макулярных разрывов составляла от 1 до 7 месяцев. По стадиям развития макулярного разрыва по Gass $[8,9]$ глаза распре-

(C) С. С. Родин, Н. Н. Уманец, Е. Г. Бражникова, А. Р. Король, Е. В. Ковалева, 2011 
делялись следующим образом: в стадии II - 28 глаз, в III стадии - 14 глаз и в IV стадии - 2 глаза. Сроки наблюдения после операции колебались от 2 месяцев до 10 лет.

Острота зрения перед операцией распределялась следующим образом: от 0,005 до 0,04 -в 7 глазах, от 0,05 до 0,1 - в 14 и от 0,12 до 0,4 - в 23 глазах. Всем больным было проведено лечение по предложенной ранее методике пневматической ретинопексии (Пат. № 31079 А Украины, МПК A61F 9/00 от 15.12.00; Бюл. № 7-11), который состоит в том, что через прокол всех оболочек глаза в проекции плоской части цилиарного тела в 3-4 мм от лимба вводят рассчитанный до операции объем газа в цистерны стекловидного тела. После операции больному придают такое вынужденное положение головы, при котором газовый пузырь находится в области разрыва сетчатки. Это положение больному предписывалось соблюдать 18-20 часов в течение 4-6 недель.

Для обеспечения длительной тампонады разрыва сетчатки необходимо достижение объема газового пузыря, занимающего не менее 40-50 \% полости стекловидного тела. В связи с этим, с целью уменьшения риска острой окклюзии центральной артерии сетчатки, необходимо использовать расширяющиеся газы с высоким коэфициентом расширения. Было признано целесообразным использование перфлюоропропана $\left(\mathrm{C}_{3} \mathrm{~F}_{8}\right)$, который постепенно расширяется в полости стекловидного тела в 4 раза в течение 2- 4 суток.

Для расчета необходимого объема газа во время операции необходимо первоначально определить величину передне-задней оси глаза по данным УЗ биометрии. Это дает возможность рассчитать внутренний радиус кривизны склеры, исходя из средних значений глубины передней камеры, радиусов кривизны и толщины роговицы и склеры [1].

Расчет внутреннего радиуса кривизны склеры производился по следующей формуле.

$$
R_{c}=\left((\Pi 30-3,6)^{2}+32.25\right) /(2 \times(\Pi 30-3,6))
$$

где $\mathbf{R}_{c}-$ внутренний радиус кривизны склеральной сферы (мм);

$$
\text { ПЗО - величина передне-задней оси глаза (мм). }
$$

Таблица 1

Величины объема склеральной сферы в зависимости от длины ПЗО глаза

\begin{tabular}{|c|c|c|}
\hline $\begin{array}{c}\text { П3О, } \\
\mathbf{M м}\end{array}$ & $\begin{array}{c}\text { Радиус кривизны внутренней } \\
\text { поверхности склеры, мм }\end{array}$ & $\begin{array}{c}\text { Объем склеральной } \\
\text { сферы (Vc), мм }\end{array}$ \\
\hline 20,0 & 9,19 & 3251 \\
\hline 21,0 & 9,64 & 3752 \\
\hline 22,0 & 10,08 & 4290 \\
\hline 23,0 & 10,54 & 4905 \\
\hline 24,0 & 11,00 & 5575 \\
\hline 25,0 & 11,46 & 6304 \\
\hline 26,0 & 11,93 & 7112 \\
\hline 24,0 & 12,40 & 7986 \\
\hline 28,0 & 12,87 & 8929 \\
\hline 29,0 & 13,34 & 9944 \\
\hline 30,0 & 13,82 & 11056 \\
\hline 31,0 & 14,29 & 12225 \\
\hline 32,0 & 14,77 & 13497 \\
\hline 33,0 & 15,25 & 14856 \\
\hline 34,0 & 15,74 & 16334 \\
\hline
\end{tabular}

В таблице 1 приведены рассчитанные величины объема склеральной сферы в зависимости от длины ПЗО глаза, произведенные по формуле расчета объема шара.
Учитывая, что перфлюоропропан $\left(\mathrm{C}_{3} \mathrm{~F}_{8}\right)$ расширяется в полости стекловидного тела в 4 раза и объем газа в полости стекловидного тела должен быть приблизительно 50 \%, т.е. 1/2 объема склеральной сферы, расчет объема газа, который необходимо ввести во время операции, будет следующим:

$$
V_{\Gamma}=V c / 4 / 2=V c / 8,
$$

где Vг - объем газа, который необходимо ввести во время операции (мм³);

\section{$\mathrm{Vc}$ - объем склеральной сферы, мм ${ }^{3}$}

РЕЗУЛЬТАТЫ И ИХ ОБСУЖДЕНИЕ. ПоЛное исчезновение макулярного разрыва через 3-4 недели после интравитреального введения расширяющегося газа достигнуто в 25 глазах $(56,8 \%)$ со II-IV стадиями разрыва. Прилегание краев разрыва после операции было отмечено в 39 глазах (88,6 \%). У больных со II стадией разрыва после длительной тампонады макулярного разрыва полное закрытие макулярного разрыва достигнуто в 23 глазах (82,2 \%), в стадиях III и IV - в 12,5 \% случаев. Прилегание краев макулярного разрыва без полного его закрытия было в 31,2 \% случаев. Острота зрения у всех больных после лечения повысилась до 0,1 -0,2 - в 19 глазах и до 0,25-0,85 в 25 глазах. Острота зрения 0,3 и выше была достигнута в $64 \%$ случаев при второй стадии разрыва сетчатки и в $19 \%$ при III и IV стадиях.

Динамика закрытия макулярного разрыва после интравитреального введения расширяющегося газа по данным оптической когерентной томографии представлена на рис. 1, 2.
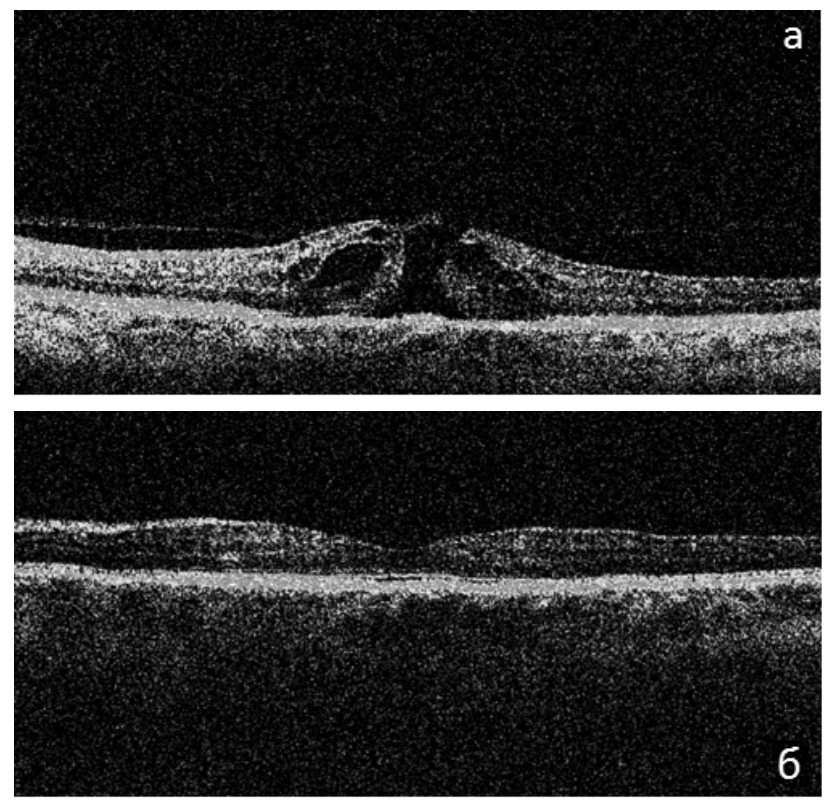

Рис. 1. а) ОКТ больного К. с макулярным разрывом во II стадии до операции, Vis = 0,2. б) OKT того же больного через 5 недель после операции, $\mathrm{Vis}=0,85$.

Отсутствие отслойки задней гиалоидной мембраны, в том числе в фовеолярной области, на глазах со II и III стадиями до лечения было диагностирова- 
но в 39 случаях, частичная или полная отслойка задней гиалоидной мембраны в макулярной области в пяти случаях (на глазах с III, IV стадиями). Через 4 -6 недель после интравитреальной инъекции расширяющегося газа отслойка стекловидного тела в макулярной области имела место в 40 глазах (91\%).
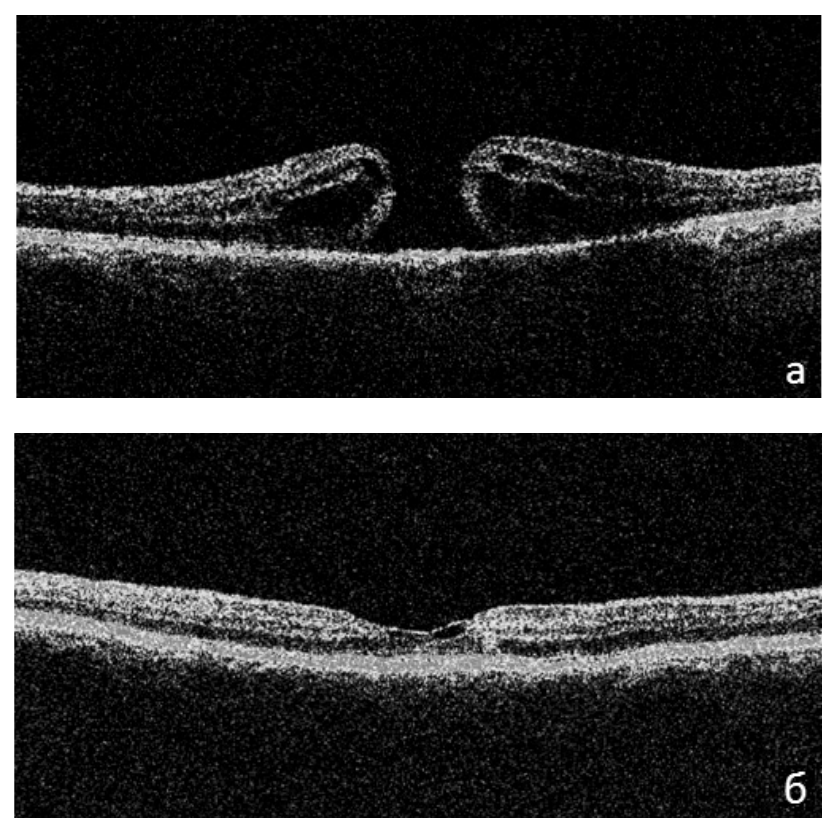

Рис. 2. а) ОКТ больного М. с макулярным разрывом во III стадии до операции, Vis $=0,2$. б) OKT того же больного через 6 недель после операции, Vis $=0,7$.

Наиболее близким к предложенному нами способу является способ лечения идиопатического разрыва сетчатки путем интравитреального введения 0,5 мл $100 \%$ расширяющегося газа $\mathrm{SF}_{6} \mathrm{c}$ соблюдением вынужденного положения головы в течение 3-5 суток [13]. Однако, использование вышеописанного способа приводит к закрытию макулярного разрыва сетчатки только у $50 \%$ пациентов. По мнению Mori с соавторами [13], к закрытию разрыва приводит индуцирование задней отслойки стекловидного тела. В публикации сообщается о 20 случаях, когда было произведено интравитреальное введение расширяющегося газа больным со второй стадией макулярного разрыва. В 19 случаях была индуцирована задняя отслойка стекловидного тела, однако закрытие разрыва сетчатки произошло в 10 из них. Исходя из нашего клинического опыта, это связано с отсутствием достаточной по длительности газовой тампонады разрыва сетчатки. С нашей точки зрения, необходимо увеличить объем и длительность газовой тампонады, что дополнительно к индуцированию задней отслойки стекловидного тела, обеспечивает формирование хориоретинального сращения по краю разрыва за счет контакта нейроэпителия сетчатки с пигментным эпителием и учащение случаев полного закрытия макулярного разрыва (82,2 против $50 \%)$.
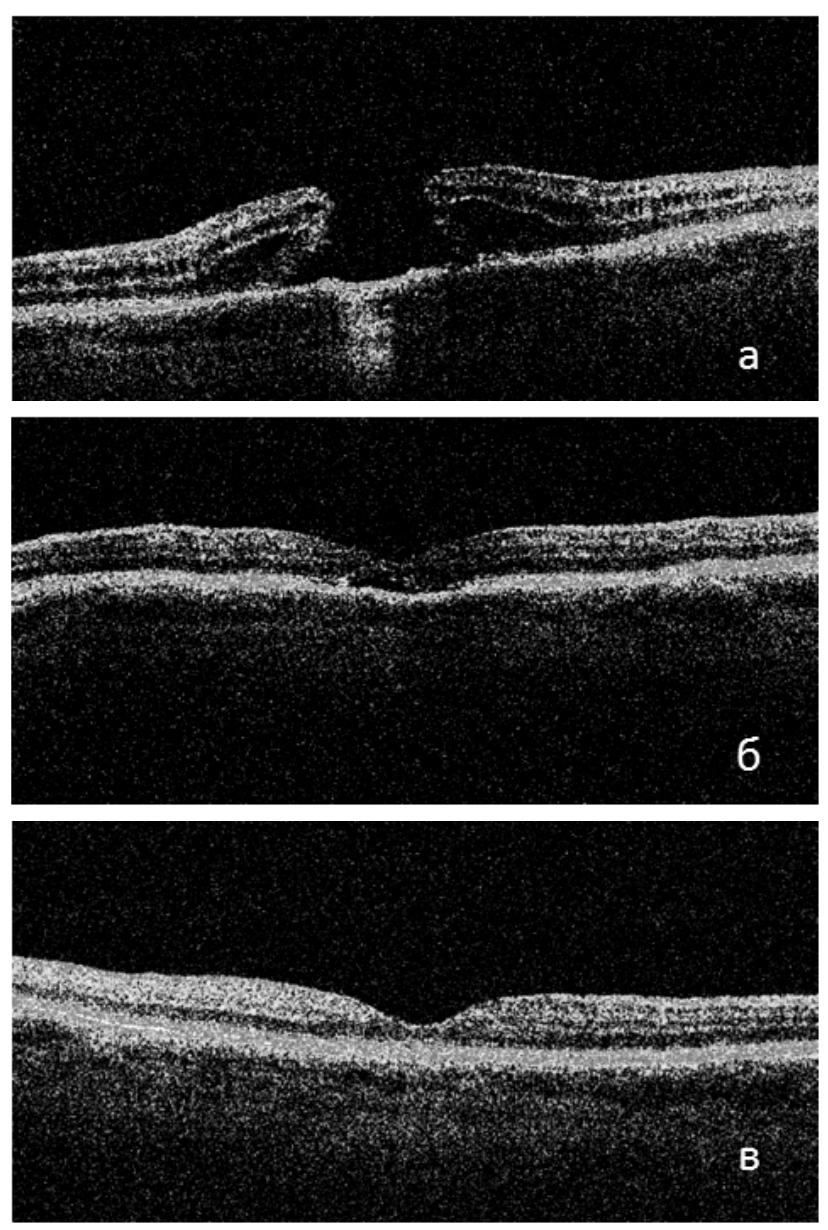

Рис. 3. а) ОКТ больного С. с макулярным разрывом во IV стадии до операции, $\mathrm{Vis}=0,14$. б) OKT того же больного через 5 недель после операции, $\mathrm{Vis}=0,5$. в) OKT того же

больного через 12 недель после операции, $\mathrm{Vis}=0,7$.

Преимуществами разработанного нами способа лечения являются:

1) длительная тампонада разрыва сетчатки путем индивидуального расчета объема газа, вводимого в полость стекловидного тела;

2) снижение травматичности операции в результате введения газа в естественные полости стекловидного тела (т.е. его цистерны), что одновременно приближает процесс формирования отслойки задней гиалоидной мембраны к естественному течению;

3) формирование отслойки задней гиалоидной мембраны обеспечивает устранение одной из причин возникновения макулярного разрыва сетчатки и в совокупности с длительной тампонадой позволяет сформировать полноценное хориоретинальное сращение в области разрыва, что и обеспечивает увеличение частоты его полного закрытия.

Mori с соавторами [13] придерживаются тактики перехода к витрэктомии в случае сохранения макулярного разрыва через 3-5 дней после интравитреального введения расширяющегося газа. С нашей точки зрения, целесообразно про- 
должение газовой тампонады даже после формирования отслойки задней гиалоидной мембраны. Целесообразность такой тактики подтверждается данными нашего исследования. В двух случаях после длительной газовой тампонады при первоначально имеющейся до операции задней отслойке стекловидного тела разрывы полностью закрылись. По нашему мнению, помимо полной отслойки задней гиалоидной мембраны и устранения при этом витреомакулярной тракции на процесс полного закрытия макулярного разрыва сетчатки влияет также другой механизм действия газового пузыря, который непосредственно воздействует на разрыв и способствует его закрытию.

Эта концепция подтверждается также данными R. F. Spaide [14]. Автор предлагает производить витрэктомию в минимальном объеме только над макулярным разрывом. В случае выявления витреоретинальных сращений в зоне разрыва автор устранял их при помощи специально сконструированного ножа и вводил расширяющийся газ в полость стекловидного тела. При применении такой тактики разрыв сетчатки полностью закрылся в трех случаях из трех. При этом автор подчеркивает, что предлагаемая операция является менее инвазивным вмешательством, чем общепринятая вирэктомия с полным удалением задней гиалоидной мембраны.

Предлагаемая Mori с соавторами тактика краткосрочного индуцирования отслойки задней гиалоидной мембраны с необходимостью последующего проведения витрэктомии в случае отсутствия закрытия разрыва сетчатки в короткие сроки (3-5 дней) с нашей точки зрения не оправдана. Так, у 45 \% пациентов, входящих в исследование Mori с соавторами [13], у которых методом интравитреального введения газа была индуцирована отслойка задней гиалоидной мембраны, из-за того, что в эти сроки не было выявлено закрытие макулярного разрыва, была проведена витрэктомия.

По данным нашего исследования, длительная газовая тампонада без индукции отслойки задней гиалоидной мембраны (полная задняя отслойка гиалоидной мембраны имела место до операции) привела к закрытию разрыва сетчатки в двух случаях из двух, что подтверждает нашу теорию влияния газового пузыря на формирование хориоретинального сращения в области разрыва.

Таким образом, простое инравитреальное введение расширяющегося газа, объем которого индивидуально рассчитан до операции, в цистерны стекловидного тела с последующим 4-6 недельным соблюдением положения головы «вниз лицом» является высокоэффективным методом лечения идиопатического разрыва сетчатки в макуле, что подтверждается данным исследованием. Этот метод значительно менее инвазивен, чем все вышеупомянутые и значительно более экономичен.

\section{ВЫВОДЫ}

1. Введение в цистерны стекловидного тела индивидуально рассчитанного объема расширяющегося газа с целью достижения в послеоперационном периоде 50 \% объема полости стекловидного тела при идиопатических макулярных разрывах с последующим 4-6 недельным соблюдением положения головы «вниз лицом» является минимально инвазивным и в то же время эффективным методом лечения данной патологии.

2. При использовании предложенного способа лечения функциональный положительный результат лечения был получен во всех случаях (100\%), анатомическое прилегание краев разрыва сетчатки было достигнуто в 88 \% случаев, полное закрытие макулярного разрыва произошло на 56,8 \% глаз со II - IV стадиями без проведения витрэктомии, а у пациентов со второй стадией в 82,2 \% случаев.

3. Предложенный метод значительно менеее инвазивен, чем комплексная витрэктомия, более экономичен и может применяться для лечения идиопатических макулярных разрывов в показанных случаях.

\section{СПИСОК ИСПОЛЬЗУЕМЫХ ИСТОЧНИКОВ}

1. Родин С. С. Новые технологии диагностики и витреоретинальной хирургии осложненных форм отслойки сетчатки: Диссертация д-ра мед. наук: 14.00.18 / Ин-т ГБ и ТТ им.В. П. Филатова. - Одесса, 2003. $402 \mathrm{c}$.

2. Wendel R.T., Patel A.C., Kelly N.E., et al. Vitreous surgery for macular holes// Ophthalmology. - 1993. - V.100. P.1671-1676.

3. Glaser B. M., Michels R. G., Kupperman B. D., et al. Transforming growth factor-beta 2 for the treatment of fullthickness macular holes: a prospective randomized study // Ophthalmology. - 1992. - V.99. - P. 1162-1172.

4. Freeman W. R., Azen S. P., Kim J.W., et al. Vitrectomy for the treatment of full-thickness stage 3 or 4 macular holes: results of a multicentered randomized clinical trial // Arch Ophthalmol. - 1997. - V.115. - P.11-21.

5. Kim J. W., Freeman W. R., Azen S. P., et al. Prospective randomized trial of vitrectomy or observation for stage 2 macular holes // Am J Ophthalmol. - 1996. - V.121. P. 605-614.

6. Paques M., Chastang C., Mathis A., et al.. Effect of autologous platelet concentrate in surgery for idiopathic macular hole: results of a multicenter, double-masked, randomized trial // Ophthalmology. - 1999. - V.106. - P.932-938.

7. Benson W. E., Cruickshanks K. C., Fong D. S., et al. Surgical management of macular holes: a report by the American Academy of Ophthalmology // Ophthalmology. 2001. - V.108. - P.1328-1335.

8. Gass J. D. Idiopathic senile macular hole: its early stages and pathogenesis // Arch Ophthalmol. - 1988. - V.106. P.629-639.

9. Gass J. D. Reappraisal of biomicroscopic classification of stages of development of a macular hole // Am J Ophthalmol. - 1995 - V.119. - P.752-759. 
10. Thompson J. T., Glaser B. M., Sjaarda R. N., Murphy R. P. Progression of nuclear sclerosis and long-term visual results of vitrectomy with transforming growth factor beta-2 for macular holes // Am J Ophthalmol. - 1995 - V.119. - P.48-54.

11. Banker A. S., Freeman W. R., Kim J. W., et al. Vision-threatening complications of surgery for full-thickness macular holes // Ophthalmology. - 1997. - V. 104. - P. 1442-1452.

12. Park S. S., Marcus D. M., Duker J. S., et al. Posterior segment complications after vitrectomy for macular hole // Ophthalmology. - 1995. - V.102. - P.775-781.
13. Mori K., Saito S., Gehlbach P. L., Yoneya S. Treatment of stage 2 macular hole by intravitreous injection of expansile gas and induction of posterior vitreous detachment // Ophthalmology. - 2007. - V. 114(1). P.127-133.

14. Spaide R. F. Macular hole repair with minimal vitrectomy // Retina. - 2003. - V.23(6). - P. 887-888.

Поступила 21.03.2011

Рецензент д-р мед. наук. А. А. Путиенко

\title{
INTRAVITREAL GAS INJECTION AS A METHOD OF SURGICAL TREATMENT OF PATIENTS WITH IDIOPATHIC MACULAR HOLES
}

\author{
S. S. Rodin, N. N. Umanets, E. G. Brazhnikova, A. R. Korol, E. V. Kovaleva \\ Odessa, Ukraine
}

The efficiency of the intravitreous gas injection (pneumatic retinopexy - PR) as a method of idiopathic macular hole (IMH) treatment of 41 patients (44 eyes) with a single intravitreous injection of perfluoropropane $\left(\mathrm{C}_{3} \mathrm{~F}_{8}\right)$ was evaluated. IMH was at the $2^{\text {nd }}$ stage in 28 eyes and at the $3^{\text {rd }}$ and $4^{\text {th }}$ stages in 16 eyes. We have used longer period of face down position (the minimum period of such position is 4 weeks) and the volume of the injected gas in its expanded state was up to $50 \%$ of the vitreous cavity. The overall rate of the macular hole closure after 4-6 weeks after gas injection was $56.8 \%$ in cases with the $2^{\text {nd }}-4^{\text {th }}$ stage of the macular hole. IMH was closed in $82.2 \%$ of cases of the $2^{\text {nd }}$ stage of the macular hole and only in $12.5 \%$ of the $3^{\text {rd }}-4^{\text {th }}$ stages of IMH. The attachment of the macular hole edges was achieved in $31.2 \%$ of cases. The improvement of visual acuity (VA) was achieved in all cases. VA $>3 / 10$ after surgery was in $64 \%$ eyes with the $2^{\text {nd }}$ stage of IMH and $19 \%$ in eyes with the $3^{\text {rd }}-4^{\text {th }}$ stages.

УДК 617.735.002-02:616.379-008.64-073

\section{РОЛЬ ВИТРЕАЛЬНОЙ ФЛЮОРОМЕТРИИ В ДИАГНОСТИКЕ ФУНКЦИОНАЛЬНЫХ И ОРГАНИЧЕСКИХ ИЗМЕНЕНИЙ ГЕМАТОРЕТИНАЛЬНОГО БАРЬЕРА У БОЛЬНЫХ ДИАБЕТИЧЕСКОЙ РЕТИНОПАТИЕЙ}

В. А. Науменко, д-р мед. н., зам.директора Института по научной и лечебной работе,

$$
\text { Н. Н. Кушнир }{ }^{\star} \text {, врач }
$$

Государственное учреждение «Институт глазных болезней и тканевой терапии им. В. П. Филатова АМН Украины»

Коммунальное учреждение «Днепропетровская областная клиническая офтальмологическая больница»*

Рівень вітреальної флюоресценції (ВФ) на 5-й хвилині після введення флюоресцеіна відображує залежність протікання барвника у скловидне тіло від ступеня вираженості органічних змін гематоретинального бар'єра. Рівень ВФ на 30-й хвилині дослідження характеризує функціональні можливості гематоретинального бар'єра за цей визначений термін. Підвищення рівня ВФ як на 5-й, так і на 30-й хвилинах дослідження при розвинутих стадіях діабетичної ретинопатії зумовлено прогрессуванням функціональних і органічних змін гематоретинального бар'єра.

Ключевые слова: Сахарный диабет, диабетическая ретинопатия, гематоретинальний барьер, витреальная флюорометрия

Ключові слова: Цукровий діабет, діабетична ретинопатія, гематоретинальний бар'єр, вітреальна флюорометрія

Введение. Нормальное функционирование сетчатки в значительной степени обеспечивается полноценностью гематоретинального барьера (ГРБ), который состоит из четко определенных клеточных слоев: пигментный эпителий сетчатки - наружный барьер, обеспечивающий активный транспорт и эндотелий сосудов сетчатки - внутренний барьер, через который происходит пассивный транспорт [1-4].

(C) В. А. Науменко, Н. Н. Кушнир, 2011 